\title{
Across-fault ground motions and their effects on some bridges in the 1999 Chi- Chi earthquake
}

\author{
Yuanzheng Lin ${ }^{1,2}$, Zhouhong Zong ${ }^{1,2^{*}}$, Jin Lin ${ }^{1,2}$, Yale Li ${ }^{3}$ and Yiyan Chen ${ }^{4}$
}

\author{
* Correspondence: zongzh@seu.edu. \\ ${ }^{1}$ Engineering Research Center of \\ Safety and Protection of Explosion \\ \& Impact of Ministry of Education \\ (ERCSPEIME), Southeast University, \\ Nanjing 211189, Jiangsu, China \\ ${ }^{2}$ School of Civil Engineering, \\ Southeast University, Nanjing \\ 211189, Jiangsu, China \\ Full list of author information is \\ available at the end of the article
}

\begin{abstract}
Simply-supported bridges are vulnerable to surface fault rupture as evidenced by several fault-crossing bridges in the 1999 Chi-Chi earthquake. To investigate the seismic collapse mechanism of simply-supported bridges crossing the fault, acrossfault ground motions are firstly simulated in the present study. In particular, based on a previously developed fault model of the 1999 Chi-Chi earthquake, broadband across-fault ground motions at six fault-crossing bridges are simulated using the hybrid deterministic-stochastic method, in which the low- and high-frequency components are computed using the deterministic Green's function method and the stochastic finite-fault modeling method, respectively. The simulation results indicate that the hybrid deterministic-stochastic method can give reasonable predictions to the across-fault ground motions. Furthermore, utilizing the explicit dynamic finite element (FE) code LS-DYNA, behaviors of a three-span simply-supported bridge under a selected pair of across-fault ground motions are numerically simulated. Numerical results indicate that the structural responses and collapse mechanisms are dominated by the low-frequency ground motions. The large differential static offset across the fault is the main reason for the collapse of the simply-supported bridges. This study contributes understandings for the across-fault ground motions and the collapse mechanism of some bridges in the 1999 Chi-Chi earthquake.

Keywords: Across-fault ground motion, Ground motion simulation, Simplysupported bridge, Seismic collapse analysis, Explicit dynamic FE model, Chi-Chi earthquake
\end{abstract}

\section{Introduction}

On 21 September 1999, a devastating earthquake of $M_{w} 7.6$ occurred in central Taiwan. The epicenter was located at $120.82^{\circ} \mathrm{E}, 23.85^{\circ} \mathrm{N}$, with a focal depth of $8 \mathrm{~km}$, and the mainshock ruptured over $100 \mathrm{~km}$ along the Chelungpu fault with a shallow dip angle of about $30^{\circ}$ to the east (Shin and Teng 2001). After the earthquake, extensive studies were performed to investigate the focal mechanism, rupture process and fault slip history (Chi et al. 2001; Ji et al. 2003; Ma et al. 2001; Wu et al. 2001). This earthquake caused significant damages to vital infrastructures including transportation bridges, roads, utilities and communication lines (Lee and Loh 2000). In particular, the

(c) The Author(s). 2021 Open Access This article is licensed under a Creative Commons Attribution 4.0 International License, which permits use, sharing, adaptation, distribution and reproduction in any medium or format, as long as you give appropriate credit to the original author(s) and the source, provide a link to the Creative Commons licence, and indicate if changes were made. The images or other third party material in this article are included in the article's Creative Commons licence, unless indicated otherwise in a credit line to the material. If material is not included in the article's Creative Commons licence and your intended use is not permitted by statutory regulation or exceeds the permitted use, you will need to obtain permission directly from the copyright holder. To view a copy of this licence, visit http://creativecommons.org/licenses/by/4.0/. 
surface fault rupture passed through seven highway bridges located along the Chelungpu fault. With either the main structure or the approach road traversed by surface fault rupture, these bridges suffered serious damages. For example, Fig. 1a shows the girder unseating of the Bei-Feng Bridge due to the large ground displacement induced by fault dislocation; Fig. 1b shows the collapse of the Tong-Tou Bridge due to the shear failure of the piers; Fig. 1c shows the severe shear failures in the columns and caissons of the Wu-Shi bridge though the bridge did not collapse (Lee and Loh 2000; NCREE 2002). In addition to these cases, damages of fault-crossing bridges were repeatedly reported in the past earthquakes, e.g. the 1999 Kocaeli and Duzce earthquakes in Turkey, and the 2008 Wenchuan earthquake in China (Han et al. 2009; Kawashima et al. 2009; Yang and Mavroeidis 2018). Although the construction of a bridge crossing a fault should be avoided from the design point of view, it is difficult to avoid existing bridges to be traversed by potential active faults due to the complexity and uncertainty of earthquake faults, especially in seismic prone areas.

Damages of fault-crossing bridges are related to the nonuniform ground movements across the fault. Somerville (2002) concluded that the displacements across a fault are discontinuous, which can subject a bridge to significant differential displacements including both quasi-static displacements and dynamic motions between the bridge supports located on two sides of the fault. Over the years, forward modeling of strong ground motion has achieved considerable progress (Papageorgiou 2003). In particular, the hybrid deterministic-stochastic method, which combines the low-frequency and high-frequency ground motions computed by the deterministic method and stochastic approach respectively (Kamae et al. 1998), has been widely adopted and proven to show reasonable predictions to the near-fault ground motions (e.g. Ding et al. 2019). However, not many studies have adopted this technique to simulate across-fault ground motions. Because the across-fault ground motions are a pair of near-fault ground motions with the two very close observation points locating on two sides of the fault, the hybrid deterministic-stochastic method is believed applicable to simulate across-fault ground motions as well. It should be mentioned that some other approaches have been developed to simulate across-fault ground motion recently. For example, across-fault ground motion can be obtained by combining the parametrically determined low-frequency pulse component and the high-frequency component of a strong-motion record (e.g. Yang et al. 2020; Zhang et al. 2020). Due to the assumption that the ground dislocation is distributed equally among the two sides of the fault, this method only applies to strike-slip fault scenario and cannot be used in dip-slip fault scenario. As a different method, the improved empirical baseline correction approach based on the target final displacement also can be used to simulate the across-fault ground motions (Lin et al.

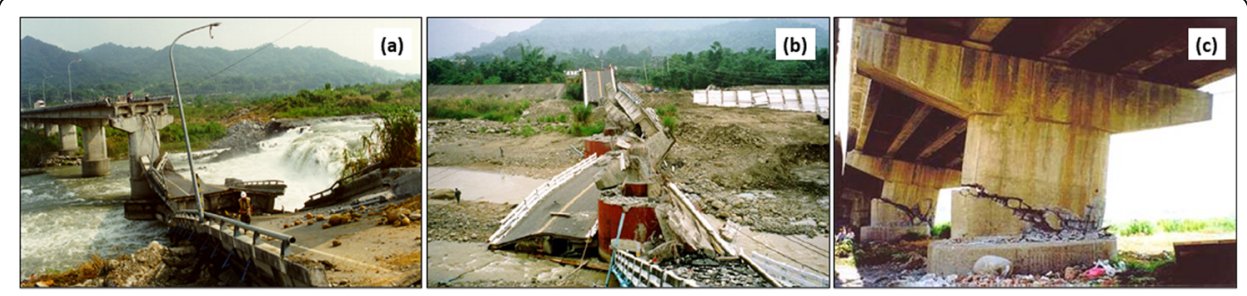

Fig. 1 Damage cases of the fault-crossing bridges in the 1999 Chi-Chi earthquake: a unseating of the BeiFeng Bridge; $\mathbf{b}$ collapse of the Tong-Tou Bridge; $\mathbf{c}$ shear failure of the Wu-Shi Bridge 
2018, 2020a, b, 2021). However, this method requires real across-fault ground motion records that are actually very rare and limited, which therefore confines the application. Because the hybrid deterministic-stochastic method is based on the earthquake source model, the above limitations can be avoided. It is necessary to use this method to simulate across-fault ground motions considering its potentional benefits for seismic performance analysis of the bridges crossing fault-rupture zones.

Some research efforts were made on the seismic behavior of bridges crossing faultrupture zones. Goel and Chopra (2009a, b) proposed linear and nonlinear analysis methods based on structural dynamics. Saiidi et al. (2013) conducted a shake table test of a two-span girder bridge crossing strike-slip fault-rupture zones. Anastasopoulos et al. (2008) proposed a methodology for the design of bridges against tectonic deformation. The Bolu Viaduct, which was traversed by the surface rupture and suffered severe damage, has been widely investigated as it survived in the 1999 Duzce, Turkey earthquake (Pamuk et al. 2005; Park et al. 2004; Roussis et al. 2003; Ucak et al. 2014). Hui (2015) did extensive investigations on the ground motion inputs, the bridge responses and the coping strategies against the effect of surface faulting. These studies primarily focused on the influence of strike-slip faults, while the responses of bridges traversed by dip-slip faults have not been sufficiently investigated (Lin et al. 2020a). It should be mentioned that different fault mechanisms can induce very different ground movements across the fault. For a strike-slip fault, the two rock blocks on the two sides of the fault move horizontally and slide past one another, which induces a reversed ground motion waveform in the fault-parallel direction but the same ground motion in the fault-normal direction on two sides of the fault. For a dip-slip fault, the two rock blocks on the two sides of the fault move downward or upward relative to each other with a dip angle to the horizontal ground surface. Depending on the fault geometry and slip properties, the across-fault ground motions of a dip-slip fault are much more complicated compared to those of a strike-slip fault (Lin et al. 2020a). Therefore, it is imperative to investigate the bridge seismic behaviors with the considerations of crossing dip-slip faults.

This paper presents a comprehensive study on the simulations of across-fault ground motions and the seismic collapse analyses of the fault-crossing bridges in the 1999 ChiChi earthquake. Following the fault model developed by Wu et al. (2001), the low- and high-frequency ground motions are computed using the deterministic Green's function method and the stochastic finite-fault modeling method respectively, and they are then combined into broadband across-fault ground motions and validated against the ground motion prediction equations (GMPEs). Furthermore, using explicit finite element (FE) code LS-DYNA, a case study of a typical simply-supported bridge is performed to investigate its seismic responses and collapse mechanism subjected to the acrossfault ground motions.

\section{Simulation of across-fault ground motions}

\subsection{Fault model}

Extensive studies have been carried out to investigate the fault rupture process and slip distribution of the 1999 Chi-Chi earthquake, and many fault models have been developed which are useful for further analyses (Chi et al. 2001; Ji et al. 2003; Ma et al. 2001; 
Wu et al. 2001). In the present study, the finite-source rupture model developed by Wu et al. (2001) is utilized to further simulate the across-fault ground motions. In particular, the entire fault plane is assumed as a rectangle with the dimensions of $84 \times 44 \mathrm{~km}$ (length $\times$ width) and is then discretized at a grid interval of $1 \mathrm{~km}$ with 3696 pieces of subfaults. On the ground surface, the fault plane has a trace with a strike of $\mathrm{N} 5^{\circ} \mathrm{E}$ and a dip angle of $30^{\circ}$. Figure 2 shows the detailed geometry of the fault model. Through an inversion using strong-motion data from 47 stations and global positioning system (GPS) data from 60 GPS stations, the fault rupture process including the slip, rake angle and rupture time of each subfault are obtained (Wu et al. 2001). Figure 2 also presents the slip distribution of the entire fault plane. It can be seen that the large slip occurs mainly in the shallow section of the faulting area in the northern part with the largest slip over $20 \mathrm{~m}$. The inversion results indicated that the reverse component is dominant in most of the faulting area, while the rupture propagates to the deep northern part with strike-slip and dip-slip components. Besides, long rise time and large slip are two significant features of the Chi-Chi earthquake from the inversion results (Wu et al. 2001). It should be mentioned that this fault model is obtained from the FiniteSource Rupture Model Database (Mai 2015), which is the simplest one (i.e. Model A) of the three models developed by Wu et al. (2001).

In this study, the aforementioned fault slip model is used to simulate the across-fault ground motions based on the hybrid deterministic-stochastic method. Because the across-fault ground motions are predicted based on the fault model by using this method, some low-frequency features incorporated in velocity pulse and permanent ground displacement at a specific site, which is strongly related to its local fault slip properties, can be accurately predicted. In addition, the discontinuity of the displacement across the fault at a specific site can also be reasonably predicted. The accurate prediction of fault dislocation features in the across-fault ground motions is a major advantage of this method compared to the other methods of ground motion simulation. However, this method requires detailed information of a fault model including geometry properties, slip distribution, risetime, rupture process and plenty of computational

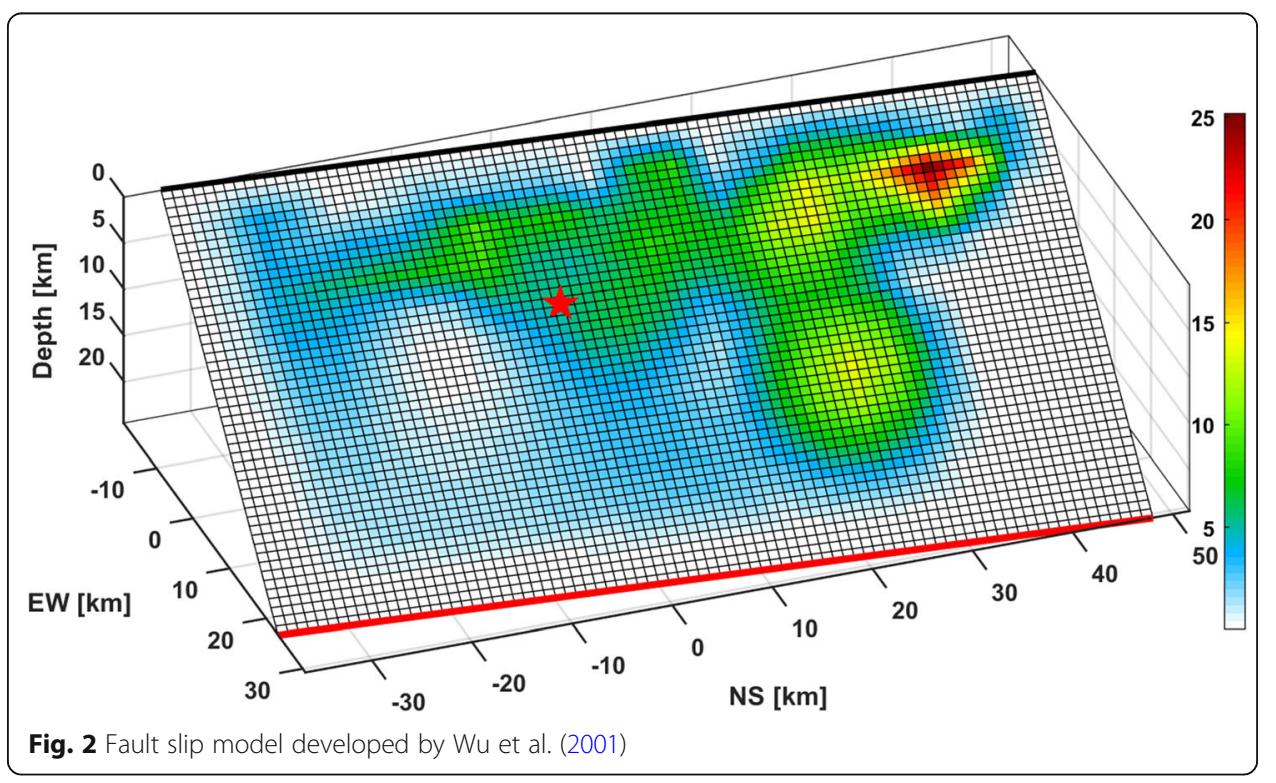


parameters, and thus it may only be used based on a well-known or validated fault model.

\subsection{Fault-crossing bridges and observation locations}

As mentioned in many earthquake reconnaissance reports for the 1999 Chi-Chi earthquake (e.g. Lee and Loh 2000; NCREE 2002), there were seven bridges traversed by the surface fault rupture. These bridges were all small or middle span simply-supported bridges, and they were constructed by T-shaped beams, single-column or thin-wall piers and elastomeric bearing pads. The damage modes of these bridges included unseating of the superstructure, shear failure and tilting of the piers and complete collapse of the structure. In particular, the unseating of the superstructure is very common and has been a major concern for the simply-supported bridges. Table 1 summarizes the locations, span arrangements and damage modes of these fault-crossing bridges.

These fault-crossing bridges are sequentially marked along the surface rupture as shown in Fig. 3a. Among them, six bridges (Site 2 to 7) located along the main rupture trace, while the Shi-Wei Bridge (Site 1) located at a secondary rupture segment bending towards the east. Along the surface fault rupture, the epicenter located between the Ming-Tsu Bridge and the Bauweishan Viaduct. Except for the Shi-Wei Bridge, the rest six bridges distributed along the main rupture of the fault. Figure $3 \mathrm{~b}$ shows the bridge locations (except for the Shi-Wei Bridge) along the assumed surface rupture for ground motion simulations, namely the assumed observation points. In particular, the locations along the surface rupture are calculated by the GPS coordinates as shown in Table 1 . In the perpendicular direction of the surface rupture, the distance from the observation points to the surface rupture is set as $500 \mathrm{~m}$ (see Fig. 3b). It should be noted that for fault-crossing bridges, the bridge supports on the two sides of the fault may be very close to the surface rupture. However, a very small fault distance may induce abnormal results for the low-frequency ground motions using the deterministic Green's function method. The reason is that Green's functions use $r^{-4}, r^{-2}$, and $r^{-1}$ forms for the near-, intermediate-, and far-field terms respectively, where $r$ is the distance from the

Table 1 Details of the fault-crossing bridges in the 1999 Chi-Chi earthquake

\begin{tabular}{|c|c|c|c|c|}
\hline Site & Bridge & GPS location & $\begin{array}{l}\text { Span } \\
\text { arrangement }\end{array}$ & Damage description \\
\hline 1 & Shi-Wei Bridge & $\begin{array}{l}120.797^{\circ} \mathrm{E} \\
24.285^{\circ} \mathrm{N}\end{array}$ & $3 \times 25 \mathrm{~m}$ & $\begin{array}{l}\text { Unseating of two spans, shear failure of piers, } \\
\text { tilting of abutments }\end{array}$ \\
\hline 2 & Bei-Feng Bridge & $\begin{array}{l}120.760^{\circ} \mathrm{E} \\
24.280^{\circ} \mathrm{N}\end{array}$ & $13 \times 30 \mathrm{~m}$ & Unseating of three spans, pier collapse \\
\hline 3 & E-Jian Bridge & $\begin{array}{l}120.734^{\circ} \mathrm{E} \\
24.133^{\circ} \mathrm{N}\end{array}$ & $24 \times 12 m$ & Unseating of 12 spans, pier collapse \\
\hline 4 & Wu-Shi Bridge & $\begin{array}{l}120.670^{\circ} \mathrm{E} \\
24.008^{\circ} \mathrm{N}\end{array}$ & $18 \times 34.8 \mathrm{~m}$ & Unseating of two spans, shear failure of piers \\
\hline 5 & $\begin{array}{l}\text { Bauweishan } \\
\text { Viaduct } \\
\text { (under } \\
\text { construction) }\end{array}$ & $\begin{array}{l}120.706^{\circ} \mathrm{E} \\
23.902^{\circ} \mathrm{N}\end{array}$ & - & $\begin{array}{l}\text { Shear failure of foundations, pounding damage } \\
\text { of abutments, tilting of piers }\end{array}$ \\
\hline 6 & Ming-Tsu Bridge & $\begin{array}{l}120.707^{\circ} \mathrm{E} \\
23.816^{\circ} \mathrm{N}\end{array}$ & $28 \times 25 \mathrm{~m}$ & $\begin{array}{l}\text { Unseating of nine spans, shear failure of piers, } \\
\text { tilting of piers }\end{array}$ \\
\hline 7 & Tong-Tou Bridge & $\begin{array}{l}120.658^{\circ} \mathrm{E} \\
23.651^{\circ} \mathrm{N}\end{array}$ & $4 \times 40 \mathrm{~m}$ & Complete collapse \\
\hline
\end{tabular}




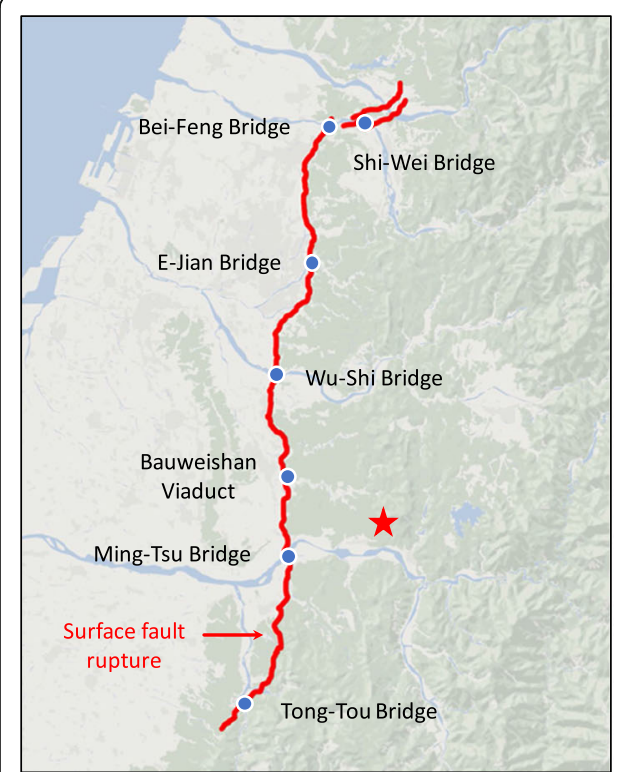

(a)

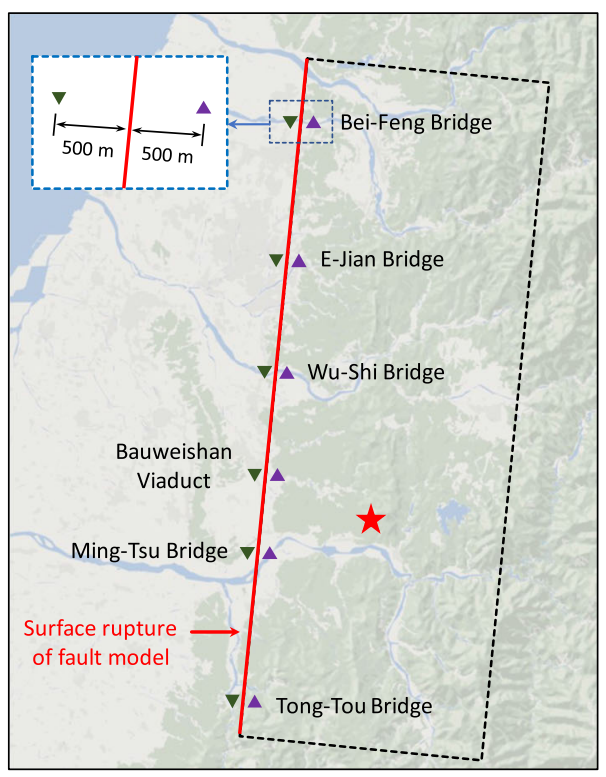

(b)

Fig. 3 Plan view of the fault-crossing bridges in the 1999 Chi-Chi earthquake: a real bridge locations; b observation points for ground motion simulation. The red lines indicate the surface fault rupture; the red star indicates the epicenter; the dashed rectangle indicates the projection of the fault model on the ground surface; and the upward and downward triangles represent the simulation locations on the hanging-wall and footwall sides, respectively

observation point to the surface rupture, and thus the traction Greens' functions will peak very sharply for a very small $r$ (Spudich and Archuleta 1987). The fault distance of $500 \mathrm{~m}$ is believed a reasonable value that is enough close to the surface rupture for simulating the ground movements while avoiding the above computational issues.

\subsection{Low-frequency ground motion}

The low-frequency component of earthquake ground motion is deterministic, which can be simulated or predicted by using a theoretical seismology model. In seismology, the deterministic method is based on the elastodynamic representation theorem proposed by Burridge and Knopoff (1964) and further developed by Aki and Richards (1980). According to this theory, the ground motion at an observation point can be computed by a spatial and temporal convolution of the Green's function with the fault slip function, which is given by

$$
u_{n}(\mathbf{x}, t)=\int_{-\infty}^{\infty} d \tau \iint_{\Sigma} \Delta u_{i}(\boldsymbol{\xi}, \tau) c_{i j p q} v_{j} \frac{\partial}{\partial \xi_{q}} G_{n p}(\mathbf{x}, t ; \boldsymbol{\xi}, \tau) d \Sigma(\boldsymbol{\xi})
$$

where $c_{i j p q}$ is the elasticity tensor, $\boldsymbol{v}$ is a unit vector normal to the fault, $\Delta u_{i}(\boldsymbol{\xi}, \tau)$ is the $i$-th component of the slip on the fault, and $G_{n p}(\mathbf{x}, t-\tau ; \boldsymbol{\xi}, 0)$ is the Green's function representing the $n$-th component of the synthetic displacement at the observation point when an impulsive source in the $p$-th direction is applied at $\mathbf{x}=\boldsymbol{\xi}$ and $t=\tau$.

In the present study, Green's functions for wave propagation are computed using the discrete wavenumber representation method (Bouchon 1979; Bouchon and Aki 1977; Olson et al. 1984). This method includes the complete response of the earth structure 
so that all the $\mathrm{P}$ and $\mathrm{S}$ waves, surface waves and near-field terms are considered. This method has been used by many researchers and proven yielding good predictions to the low-frequency near-fault ground motions (e.g. Ding et al. 2019; Wu et al. 2001). In the present study, a horizontally layered velocity structure is assumed, which is tabulated in Table 2. This layered velocity structure model is obtained from the FiniteSource Rupture Model Database (Mai 2015) and is slightly different from the models provided by Wu et al. (2001) It should be mentioned that no special efforts are made to compare the results using different layered velocity structure models, nevertheless, this model is believed reasonable to predict ground motions.

For a finite-source rupture model, the slip on a subfault is time-dependent and can be characterized by rupture onset time, slip rate and slip duration (i.e. risetime). The fault slip function can be given by

$$
\Delta u_{i}(\boldsymbol{\xi}, t)=\Delta u_{i}(\boldsymbol{\xi}) s(t, \boldsymbol{\xi})
$$

where $\Delta u_{i}(\boldsymbol{\xi})$ is the final slip, and $s(t, \boldsymbol{\xi})$ is the slip rate and risetime function. In the present study, a boxcar function is adopted as the fault slip rate-time function, which is shown in Fig. 4. The boxcar function has a simple form and can achieve permanent displacement due to its asymmetric form. When the fault rupture arrives at a given subfault, the corresponding slip at the subfault occurs. The slip trigger time of each subfault depends on the rupture propagation process. Previous studies concluded that the rupture velocity varies from 1.6 to $4.0 \mathrm{~km} / \mathrm{s}$ in different regions of the fault plane with an average value of about $2.5 \mathrm{~km} / \mathrm{s}$ (Chi et al. 2001; Ji et al. 2003; Ma et al. 2001; Wu et al. 2001). In this study, a constant rupture velocity of $2.5 \mathrm{~km} / \mathrm{s}$ is assumed and used to determine the rupture onset time of each subfault. In addition to the Green's function and the fault slip function, some other parameters are properly selected for simulating the ground motions. In particular, the maximum frequency for computing Green's functions is set as $1.0 \mathrm{~Hz}$, the seismic moment is set as $2.7 \times 10^{20} \mathrm{~N} \cdot \mathrm{m}$ according to the solution from Wu et al. (2001) and the duration of the simulated ground motions is set as $90 \mathrm{~s}$.

Figure 5 shows the simulation results of the low-frequency across-fault ground motions at each bridge site. For a straightforward demonstration, the across-fault ground motions have been processed using a low-pass filter with the cut-off frequency of 0.50

Table 2 Layered velocity structures

\begin{tabular}{llll}
\hline Depth $(\mathbf{k m})$ & $\boldsymbol{V}_{\boldsymbol{p}}(\mathbf{k m} / \mathbf{s})$ & $\boldsymbol{V}_{\boldsymbol{s}}(\mathbf{k m} / \mathbf{s})$ & Density $\left(\mathbf{t} / \mathbf{m}^{\mathbf{3}}\right)$ \\
\hline 0.00 & 2.88 & 1.55 & 2.00 \\
0.91 & 3.15 & 1.70 & 2.05 \\
1.91 & 4.37 & 2.50 & 2.30 \\
3.70 & 5.13 & 2.85 & 2.40 \\
8.00 & 5.90 & 3.30 & 2.60 \\
13.00 & 6.21 & 3.61 & 2.70 \\
17.00 & 6.41 & 3.71 & 2.75 \\
25.00 & 6.83 & 3.95 & 2.80 \\
30.00 & 7.29 & 4.21 & 3.00 \\
35.00 & 7.77 & 4.49 & 3.10 \\
50.00 & 8.05 & 4.68 & 3.10 \\
\hline
\end{tabular}




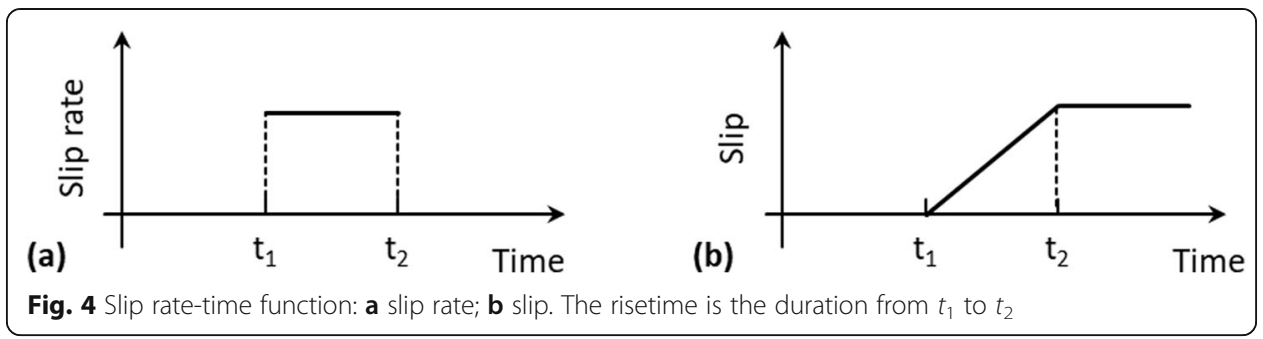

Hz. It can be seen from Fig. 5 that the simulated low-frequency ground motions are very different along the main fault rupture (from Site 2 to 7). In particular, the simulated ground motions in the northern regions (e.g. Site 2) shows larger peak ground accelerations (PGAs), peak ground velocities (PGVs) and peak ground displacements (PGDs) than those in the southern regions (e.g. Site 7), which can be explained by the following two reasons. The main reason is that the low-frequency ground motions at these observation points are mainly dominated by the fling-steps, which are related to the local fault slip as shown in Fig. 2, in which the fault slip increases gradually from south to north. The other reason is that the epicenter located in the southern region, and with the fault breaking from south to north, forward directivity effect occurs when the rupture propagates to the northern regions, which further enhances the pulse components. It is also noted in Fig. 5 that the ground motions on the two sides of the fault are significantly different at a specific site. In particular, the ground motions on the hanging-wall side show larger intensities compared to the corresponding ground motions on the footwall side due to the hanging-wall effect. In addition, the permanent ground displacements on the hangingwall side are also significantly larger than the corresponding components on the footwall side, implying the ground movements mainly occur on the hanging-wall, moving upwards relative to the footwall. Different permanent ground displacements on the two sides of the fault induce significant differential displacements across the fault. For example, the ground motions at the Bei-Feng Bridge (No. 2) show permanent differential displacements of $5.7 \mathrm{~m}, 3.4 \mathrm{~m}$ and $7.4 \mathrm{~m}$ in the vertical, fault-parallel and fault-normal directions respectively, which can be very dangerous for the fault-crossing bridges.

\subsection{High-frequency and broadband ground motions}

The high-frequency component of the ground motion is fundamentally different from the low-frequency component, showing strong stochastic behavior, which is random and difficult to be depicted by the theoretical seismology model. In the present study, the high-frequency ground motions are simulated based on the stochastic method described by Boore $(1983,2003)$ In this method, the primary consideration is to determine the spectrum of the ground motion, which can be given by

$$
Y\left(M_{0}, R, f\right)=E\left(M_{0}, f\right) P(R, f) G(f) I(f)
$$

where $M_{0}$ is the seismic moment; $E\left(M_{0}, f\right)$ is the source spectrum function, and its amplitude can be determined by $M_{0} ; P(R, f)$ represents the path effect function that accounts for the geometrical spreading, attenuation, and the general increase of duration with distance due to wave propagation and scattering; $G(f)$ is the local site effect function, which is used to consider the amplification due to local site geology and the attenuation due to path-independent loss of energy; $I(f)$ is an operator determining the 


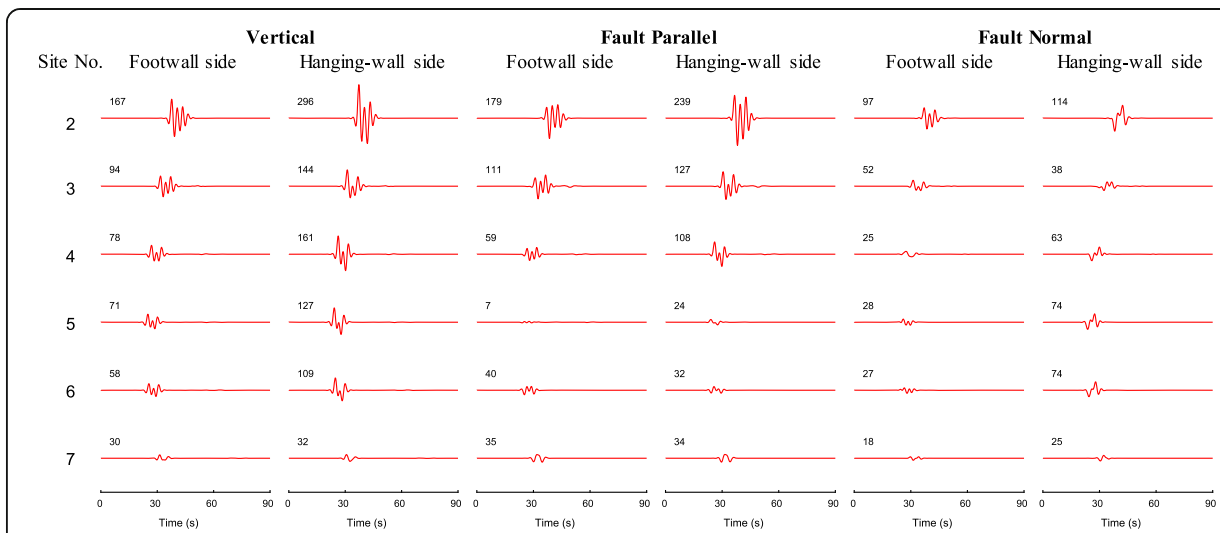

(a)

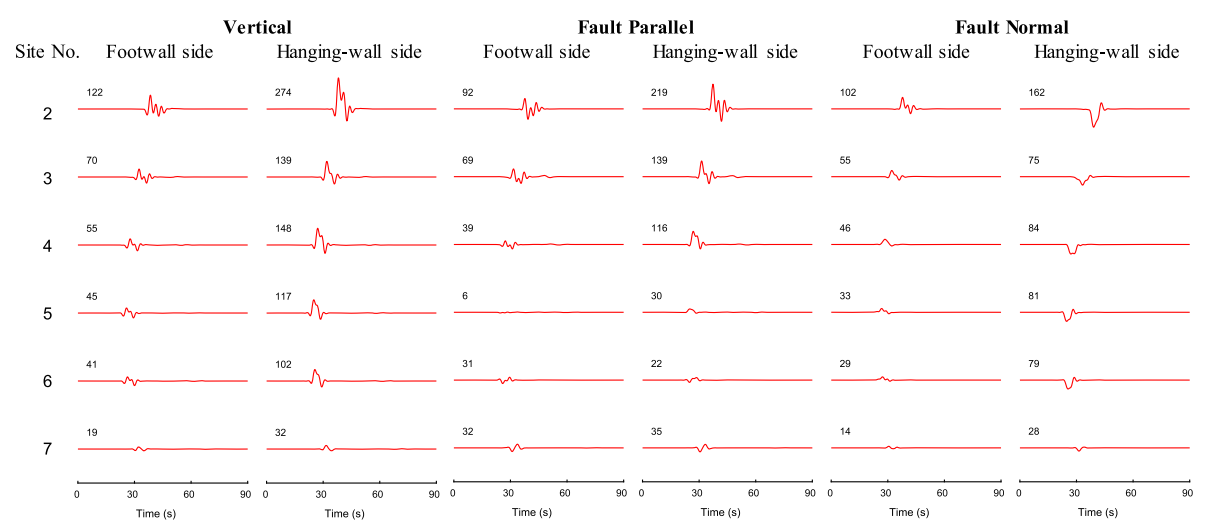

(b)

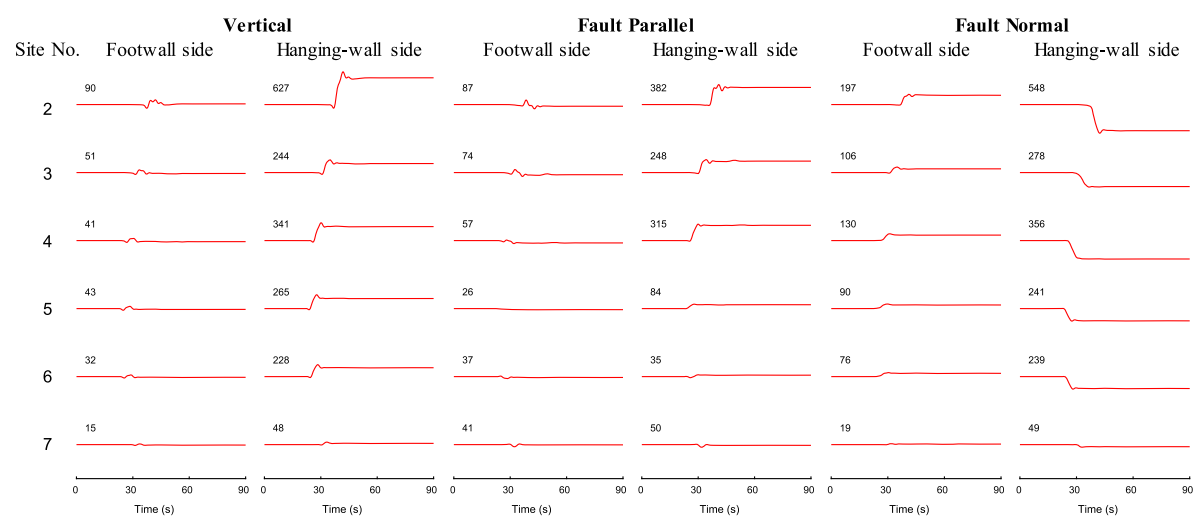

(c)

Fig. 5 Simulation results of the low-frequency ground motion time histories at each bridge site: a acceleration; $\mathbf{b}$ velocity; $\mathbf{c}$ displacement. The number of each subplot indicates the peak value with the unit in $\mathrm{cm} / \mathrm{s}^{2}, \mathrm{~cm} / \mathrm{s}$ and $\mathrm{cm}$ for acceleration, velocity and displacement, respectively. The numbers on the left correspond to the bridges listed in Table 1

type of the output ground motion (i.e. acceleration, velocity or displacement output). This method is also referred to as the stochastic point-source method.

In a large earthquake, the source properties including fault geometry, slip distribution and directivity, etc., can significantly influence the ground motion at the observation point near the fault. To incorporate these factors, a large fault can be divided into $N$ 
pieces of subfaults with each one considered as a small point source. The rupture spreads radially from the hypocenter and triggers slips on subfaults sequentially. The ground motions induced by each subfault is calculated by the stochastic point-source method, and these ground motions are summed with a proper time delay to obtain the ground motion for the entire fault (Motazedian and Atkinson 2005), which can be given by

$$
a(t)=\sum_{i=1}^{N_{l}} \sum_{j=1}^{N_{w}} a_{i j}\left(t+\Delta t_{i j}\right)
$$

where $N_{l}$ and $N_{w}$ represent the number of the subfaults along the length and width of the fault plane, respectively $\left(N_{l} \times N_{w}=N\right) ; \Delta t_{i j}$ is the relative delay time for the radiated wave from the $i j$-th subfault to reach the observation point; $a_{i j}$ is the ground motion at the observation point due to each subfault, which is calculated by the stochastic pointsource method. This stochastic finite-fault modeling technique has been a useful tool for the prediction of near-fault ground motions of a large earthquake. In the present study, the high-frequency ground motions are simulated using the source-based stochastic finite-fault code EXSIM developed by Motazedian and Atkinson (2005) This computer code has been widely used to predict the near-fault ground motions with fair accuracy in the high-frequency range (e.g. Sun et al. 2015).

Some studies have been performed to predict the ground motions in the 1999 ChiChi earthquake using the stochastic finite-fault modeling method (e.g. D'Amico et al. 2012; Lekshmy and Raghukanth 2019; Liu et al. 2012; Roumelioti and Beresnev 2003). In the present study, the fault model for computing high-frequency ground motion is consistent with that used in the low-frequency ground motion simulation as demonstrated in Section 2.1. The modeling parameters used in EXSIM are mainly from D'Amico et al. (2012) as tabulated in Table 3. In particular, the parameters regarding the crustal properties, attenuation and geometric spreading, etc., have been validated against the observation results. The crustal amplification is considered using the NEHRP site class C $\left(V_{s 30}=520 \mathrm{~m} / \mathrm{s}\right)$ as given by Boore et al. (1997).

It should be mentioned that the EXSIM program is primarily developed to simulate the horizontal earthquake ground motions, with no special intention for the vertical ground motions. In the present study, the vertical ground motions are obtained through scaling the horizontal ground motions by an empirical vertical to horizontal $(\mathrm{V} / \mathrm{H})$ ratio of 0.64 . This scale factor is determined by the average $\mathrm{V} / \mathrm{H}$ ratios of 130 strong-motion records from the 1999 Chi-Chi earthquake (Wang et al. 2002). It should be noted that this simplified approach to obtain the vertical ground motions has no significant influence on the simulation results.

The broadband across-fault ground motions are obtained by combining the corresponding low- and high-frequency ground motions in the time domain, and a matched low- and high-pass filters at the cut-off frequency of $0.50 \mathrm{~Hz}$ is used. Figure 6 shows the broadband across-fault ground motions at the selected six bridge sites. It can be seen that the simulated broadband across-fault ground motions are very different on the two sides of the fault. In particular, the PGAs on the hanging-wall side are on average $24 \%$ larger than those on the footwall side due to the hanging-wall effect. In addition, while the across-fault ground motions at different sites along the fault rupture 
Table 3 Modeling parameters for the 1999 Chi-Chi earthquake in EXSIM

\begin{tabular}{ll}
\hline Parameter & Value \\
\hline Moment magnitude & 7.6 \\
Stress drop $\Delta \sigma$ (bar) & 90 \\
Kappa (s) & 0.05 \\
Fault orientation (strike/dip) & $5^{\circ} / 30^{\circ}$ \\
Fault dimensions (length $\times$ width) & $84 \mathrm{~km} \times 44 \mathrm{~km}$ \\
Subfault dimensions & $1 \mathrm{~km} \times 1 \mathrm{~km}$ \\
Slip distribution & Wu et al. $(2001)$ \\
Crustal shear-wave velocity (km/s) & 3.2 \\
Crustal density (g/cm ${ }^{3}$ ) & 2.8 \\
Rupture to shear-wave velocity ratio & 0.8 \\
Anelastic attenuation, Q( $f)$ & $350(f)^{0.32}$ \\
Geometric spreading &
\end{tabular}

show varying PGAs, the northern observation points generally show greater PGAs than those in the southern areas. The reason is that very large slips occur in the northern areas (see Fig. 2), where the effect of forward directivity is also more prominent compared to the southern areas. It also can be observed from Fig. 6 that the broadband across-fault ground motions exhibit some differences in the PGVs and PGDs when compared to the corresponding low-frequency ground motions as shown in Fig. 5. However, the waveforms of the velocity pulses are not significantly affected and the displacement time histories are almost unchanged, implying the velocity and displacement time histories of the across-fault ground motions are primarily dominated by the lowfrequency components.

It should be mentioned that as observed in Section 2.3, differential displacements exist across the fault, which is also incorporated in the broadband across-fault ground motions. Thus, for the thrust fault considered in this study, the hanging-wall effect and the permanent differential displacements across the fault are two main characteristics of the across-fault ground motions, which may have significant impacts on the faultcrossing bridges. As will be presented in Section 3, simply supported bridges can be very vulnerable and may suffer structural collapse due to surface faulting movements.

\subsection{Comparison to ground-motion prediction equations}

Since there are hardly any available ground motion records at or very close to the faultcrossing bridges, the simulated across-fault ground motions are compared to the GMPEs. In the present study, the GMPE proposed by Abrahamson et al. (2014), namely ASK14, is used for comparison. In particular, ASK14 allows the regionalization of $V_{s 30}$ scaling and the anelastic attenuation for Taiwan, and also considers the scaling for the 


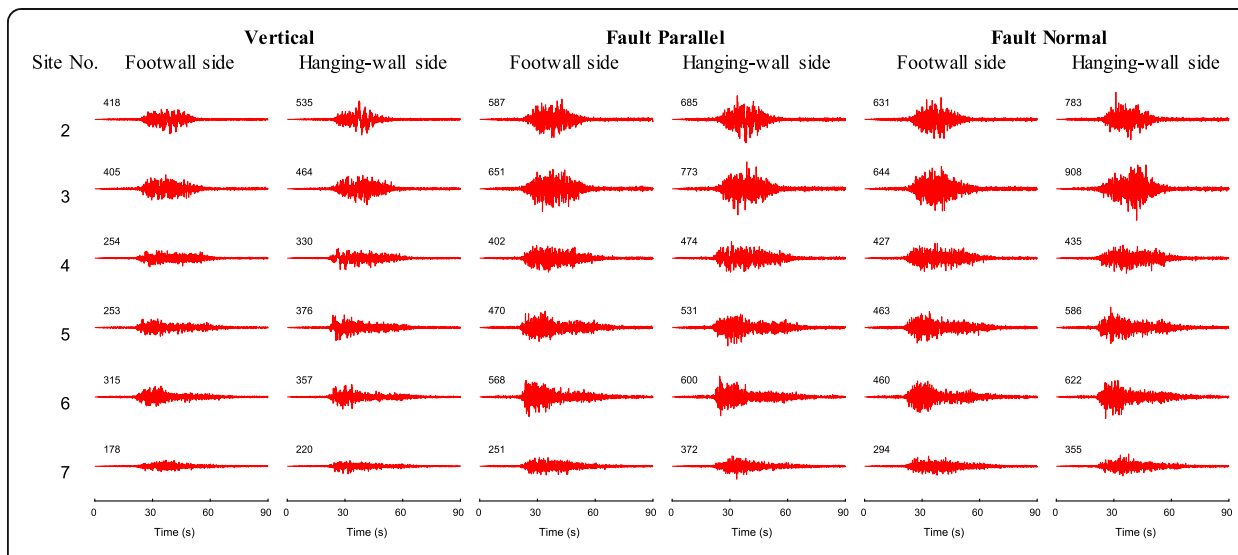

(a)
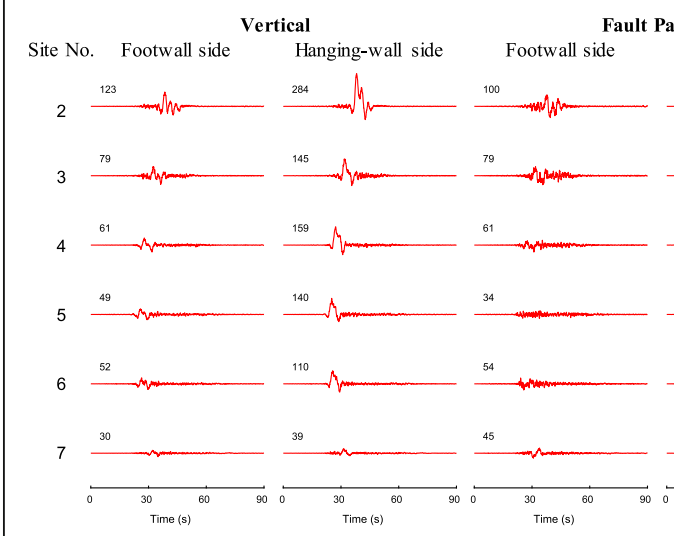

\section{arallel}

Hanging-wall side

Fault Normal

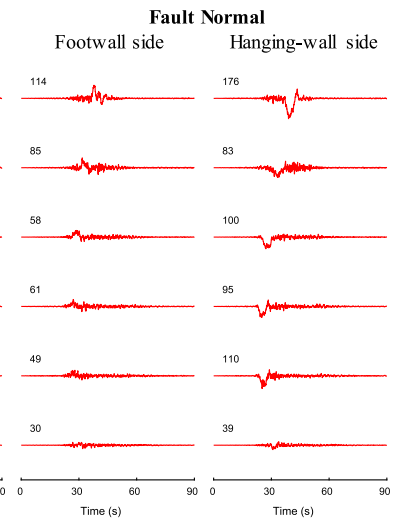

(b)

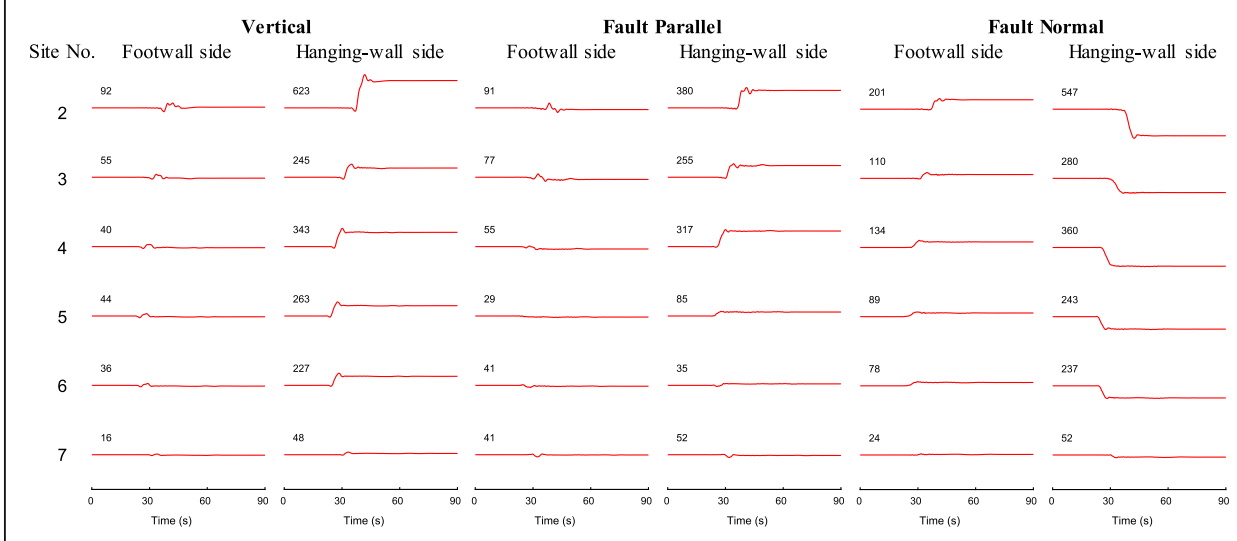

(c)

Fig. 6 Simulation results of the broadband ground motion time histories at each bridge site: a acceleration; b velocity; c displacement. The number of each subplot indicates the peak value with the unit in $\mathrm{cm} / \mathrm{s}^{2}$, $\mathrm{cm} / \mathrm{s}$ and $\mathrm{cm}$ for acceleration, velocity and displacement, respectively. The numbers on the left correspond to the bridges listed in Table 1

hanging-wall effect. The input parameters for ASK14 are all consistent with the previously described fault models, and they are tabulated in Table 4.

Figure 7 compares the elastic pseudo-acceleration response spectra ( $5 \%$ damping) between the simulated horizontal across-fault ground motions and the GMPE ASK14. It can be seen that the mean value of the simulations (blue dashed line) is close to the 
Table 4 Input parameters for GMPE ASK14

\begin{tabular}{ll}
\hline Parameter & Value \\
\hline Moment magnitude & 7.6 \\
The closest distance to the ruptured plane, $R_{\text {rup }}(\mathrm{km})$ & $0.25 / 0.5$ for hanging-wall/footwall \\
Joyner-Boore distance, $R_{j b}(\mathrm{~km})$ & $0 / 0.5$ for hanging-wall/footwall \\
$R_{x}(\mathrm{~km})$ & 0.5 \\
$R_{\text {yo }}(\mathrm{km})$ & 0 \\
Depth to the top of rupture plane, $Z_{\text {tor }}(\mathrm{km})$ & 0 \\
Fault dip/rake angle & $30^{\circ} / 55^{\circ}$ \\
Down-dip rupture width $(\mathrm{km})$ & 44 \\
Region & Taiwan \\
$V_{s 30}(\mathrm{~m} / \mathrm{s})$ & 520 \\
\hline
\end{tabular}

ASK14 predicted results (bold red line). The simulation results (12 horizontal ground motions on the hanging-wall and footwall respectively) are generally within the range between the predicted value plus or minus one standard deviation. Therefore, it is believed that the simulation results can give reasonable predictions to the across-fault ground motions.

It should be mentioned that as can be observed from Fig. 7, some simulation results exceed the predicted range (i.e. the predicted value plus or minus one standard deviation) in the long period range. This is expected since the simulated across-fault ground motions are from the observation points located very close to surface rupture, where large long-period components are prominent due to the fling-step effect. However, the strong-motion records for the regression of ASK14 distributed over a large seismic area and can not accurately reflect the local situation very close to the fault.

\section{Bridge collapse analyses}

\subsection{Bridge details}

In this section, a case study is presented to investigate the collapse failure mechanism of the fault-crossing bridges in the 1999 Chi-Chi earthquake. As mentioned in Section 2.2, most of the fault-crossing bridges were multi-span simply-supported bridges (see

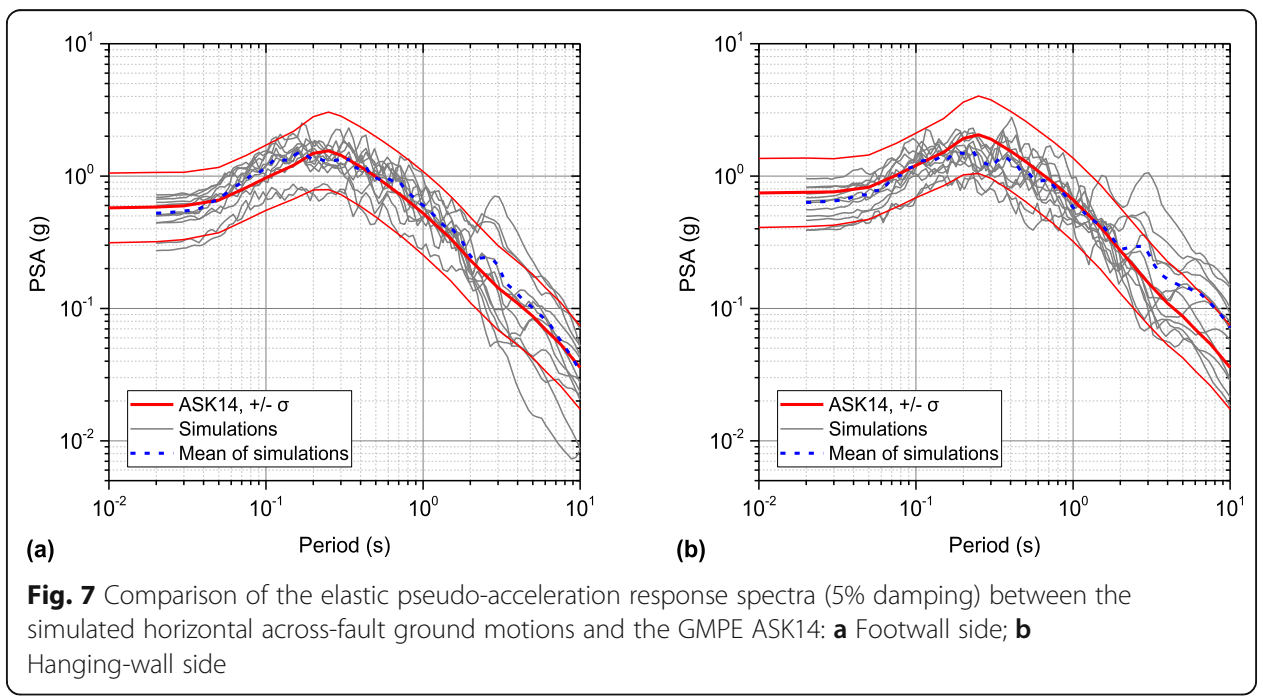




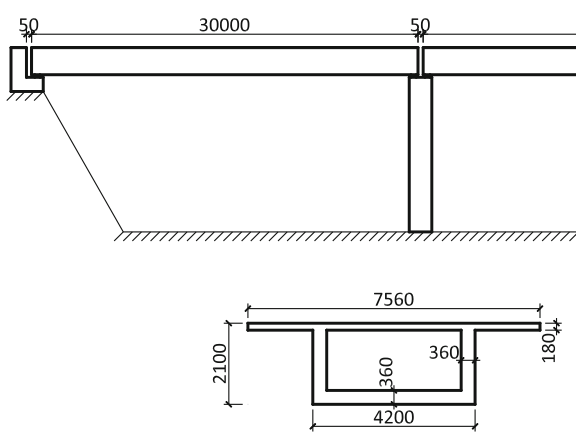

(b)

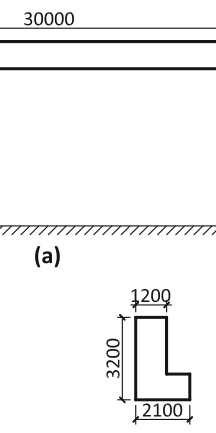

(c)

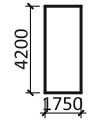

(d)

Fig. 8 Geometry of the bridge: a elevation view; cross-section of $\mathbf{b}$ bridge girder, $\mathbf{c}$ abutments and $\mathbf{d}$ bridge piers (unit: $\mathrm{mm}$ )

Table 1). Thus, a three-span simply-supported girder bridge with a similar engineering background is considered herein. Figure 8 shows the geometry of the bridge. In particular, the superstructure consists of three spans of simply-supported reinforced-concrete box girders with a length of $30 \mathrm{~m}$ for each span (see Fig. $8 \mathrm{a}$ and b). The bridge piers are single-column reinforced concrete bents with a height of $12 \mathrm{~m}$ and a rectangular crosssection of $4.2 \times 1.75 \mathrm{~m}$ (see Fig. $8 \mathrm{~d}$ ), and they support the bridge girders through two rows of rubber bearings beneath the girder end of each span. L-type abutments are placed at the two ends of the entire bridge (see Fig. 8c) to confine the longitudinal movement of the bridge superstructure. Expansion joints with a gap of $50 \mathrm{~mm}$ are introduced between the adjacent girders and abutments where seismic poundings may occur. With a similar engineering background compared to the fault-crossing bridges in the Chi-Chi earthquake, it is believed that this bridge model can reflect some essential characteristics of this type of bridge with respect to structural responses and damage modes under the across-fault ground motions.

\subsection{Explicit dynamic FE model}

\subsubsection{Element and material properties}

A detailed 3D explicit dynamic finite element model of the bridge is developed using ANSYS/LS-DYNA (LSTC 2016). The main structure of the bridge is constructed by constant stress 8-node solid element, and the reinforcements are modeled by beam element. The material models MAT_CONCRETE_DAMAGE_REL3 (MAT_072R3) and MAT_PIECEWISE_LINEAR_PLASTICITY (MAT_024) are adopted to model the concrete and reinforcements respectively at the end regions of the bridge girder, as well as the potential contact sides of the abutments, with a fine mesh size of $60 \mathrm{~mm}$. This modeling can simulate very detailed damages at the local regions where seismic poundings may occur. The material model MAT_PSEUDO_TENSOR (MAT_016) is used to model the reinforced concrete of the other parts of the bridge, namely a smeared model with a coarse mesh is used. The combination of these two modeling techniques for reinforced concrete can achieve satisfied simulation results with a relatively low cost of computational effort, which have been used by many researchers and proven yielding good results (e.g. Bi and Hao 2013; Lin et al. 2020a; Tang and Hao 2010). The elastomeric bearing pads supporting each span are modeled by the material model 
Table 5 Material properties

\begin{tabular}{lllll}
\hline Material & $\boldsymbol{E}(\mathrm{GPa})$ & $\boldsymbol{f}_{\boldsymbol{c}}{ }^{\prime}(\mathbf{M P a})$ & $\boldsymbol{f}_{\boldsymbol{t}}$ or $\boldsymbol{f}_{\boldsymbol{y}}(\mathbf{M P a})$ & $\boldsymbol{\rho}\left(\mathbf{k g} / \mathbf{m}^{\mathbf{3}}\right)$ \\
\hline Concrete & - & 50 & 5 & 2400 \\
Reinforcement & 200 & - & 550 & 7850 \\
Elastomeric bearing pad & 0.182 & - & - & 2300 \\
\hline
\end{tabular}

MAT_VISCOELASTIC (MAT_006). The material properties of the bridge model are tabulated in Table 5. In addition, MAT_ADD_EROSION is introduced to delete highly deformed elements when the maximum principal strain reaches 0.15 .

The strengths of the structural materials can be enhanced due to the strain rate effect under dynamic loads. Therefore, the dynamic increase factor (DIF), i.e. a ratio of the dynamic to static strength against strain rate to account for the material strength enhancement with strain rate effect, is utilized to account for the material strength enhancement effect for both concrete and reinforcement materials. In the present study, the bilinear relationship developed by CEB code (Beton CE-Id 1990) and Malvar and Ross (1998) are applied for the concrete compression and tensile strength enhancement respectively, and the $\mathrm{K} \& \mathrm{C}$ model (Malvar 1998) is utilized to determine the DIF for the reinforcement bars.

\subsubsection{Boundary conditions and input ground motions}

Contacts between the bridge members are considered in the FE model. In particular, these contacts include the poundings between the adjacent girder segments, the sliding between girders and bearings, and the frictions between girders and piers. In addition, the ground surface is modeled with a rigid plane so that the impact between the bridge girder and the ground surface can be simulated when girder unseating occurs. The contact algorithm CONTACT_AUTOMATIC_SURFACE_TO_SURFACE is employed for all the potential contact interfaces. By using this contact algorithm, the Coulomb friction needs to be specified, which is set to be 0.5 in this study (Jankowski 2012).

The bridge model is assumed to cross the surface fault rupture in the normal direction (see Fig. 9), namely a fault-crossing angle of $90^{\circ}$ is considered, and the longitudinal

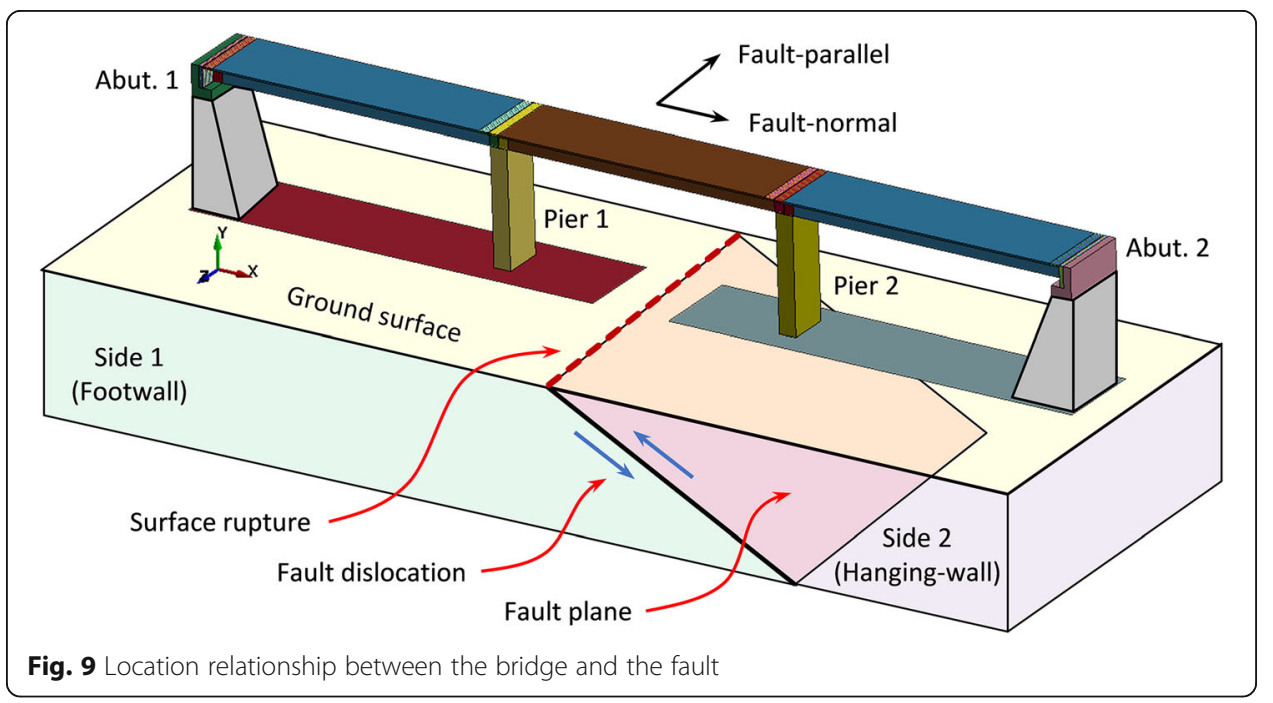


and transverse directions of the bridge point to the fault-normal and fault-parallel directions, respectively. The surface fault rupture locates beneath the middle span, and the left (i.e. Abutment 1 and Pier 1) and right spans (i.e. Abutment 2 and Pier 2) are located on Sides 1 and 2, respectively (see Fig. 9). All the bridge supports are fixed on the ground, namely earthquake excitations are directly applied to all the piers and abutments. Without loss of generality, a typical pair of across-fault ground motions simulated at Site 5 (see Fig. 6) is selected as the seismic inputs, with $60 \mathrm{~s}$ of strong-motion duration extracted as shown in Fig. 10. This pair of across-fault ground motions have moderate PGAs and can simulate the quasi-static ground movements of a thrust fault. In particular, the differential displacements in the longitudinal, transverse and vertical directions are $3.03 \mathrm{~m}, 0.94 \mathrm{~m}$ and $2.08 \mathrm{~m}$, respectively, i.e. the dip-slip component is dominant while the strike-slip component is insignificant. It should be mentioned that since the middle span of the bridge crosses the fault, the input ground motions are different for left and right spans. In particular, "Side 1" ground motion is applied to Abutment 1 and Pier 1, while "Side 2" ground motion is applied to Abutment 2 and Pier 2 (see Figs. 9 and 10).

\subsection{Numerical results and discussion}

Figure 11 shows the collapse process of the bridge subjected to the selected across-fault ground motions. As shown, due to the static offset in the longitudinal direction, the two abutments move close to each other, reducing the gaps of the expansion joints, and then poundings occur between the different girder segments and the adjacent abutments at around $9.0 \mathrm{~s}$. With the ground surface of Side 2 moving toward Side 1 continuously, Pier 2 is imposed to translate toward the negative $\mathrm{X}$ direction while the movements of the girder segments are restricted due to the boundary confinement from Abutment 2. When the right span loses vertical support from Pier 2, it separates and unseats from Pier 2, which is captured at $9.6 \mathrm{~s}, 10.0 \mathrm{~s}, 10.5 \mathrm{~s}$ and $11.1 \mathrm{~s}$ as shown in Fig. 11, and the final status of the bridge can be observed at $20.0 \mathrm{~s}$. It is noted that the right end of the right span remains on the abutment, and the reason is that Abutment
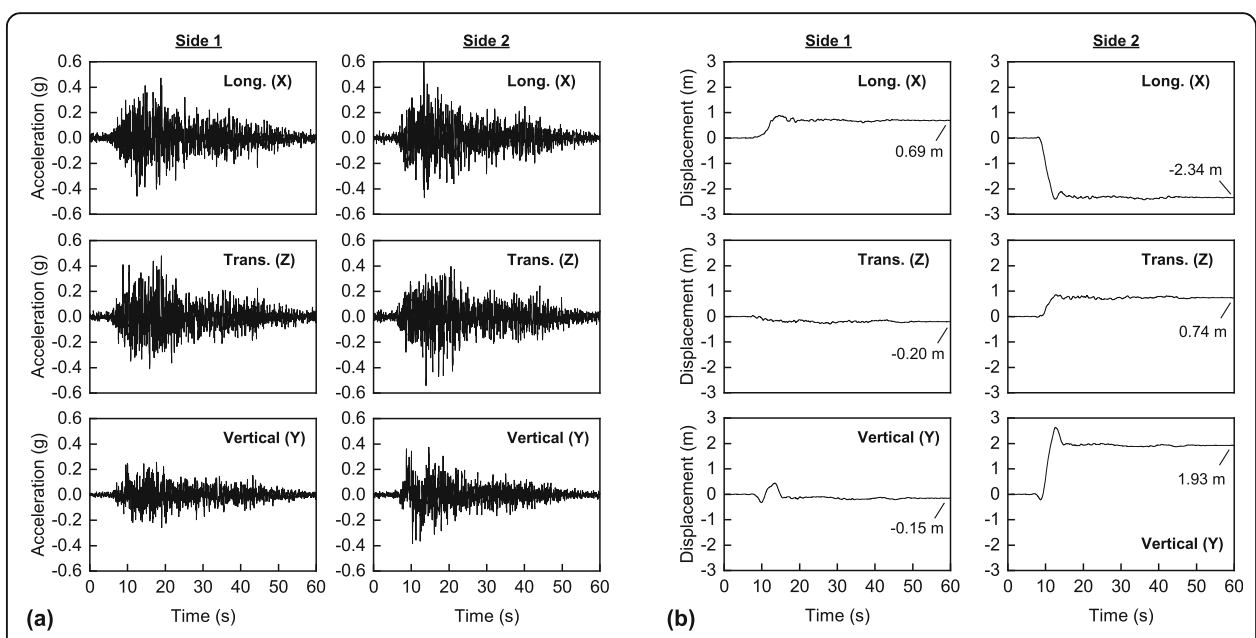

Fig. 10 Time histories of the input ground motions (simulated at Site 5): a acceleration; b displacement 


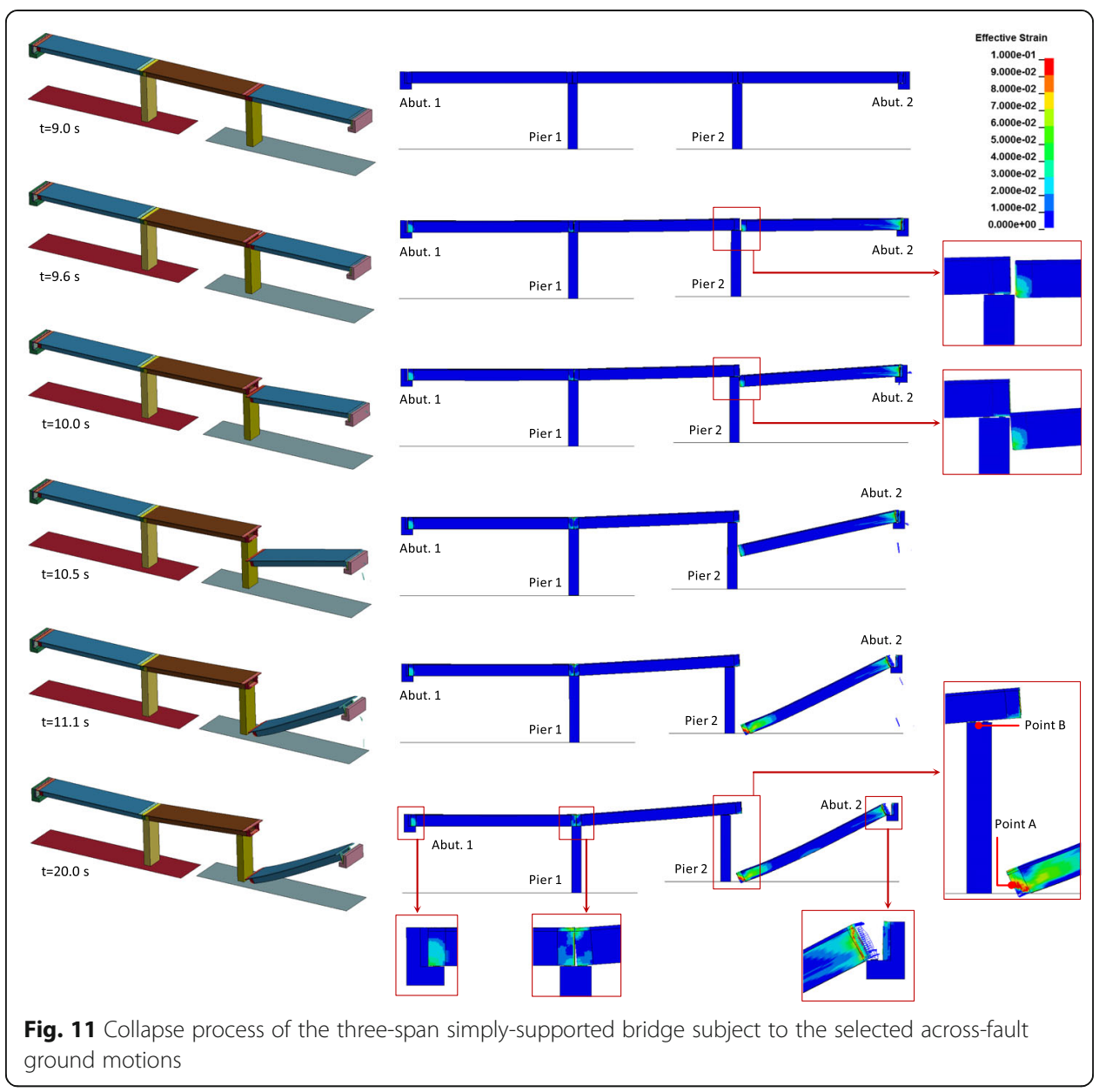

2 provides a sufficient supporting length for the right span when moving toward the negative $\mathrm{X}$ direction.

It also can be noted from Fig. 11 that while unseating does not occur to the other two spans, certain damages and different final status are however obtained due to the fault dislocation. In particular, the left and middle spans suffer pounding damages at the girder ends with the gaps of expansion joints compressed. For the middle span, due to the vertical static offset of Side 2, its right end is significantly lifted up through Pier 2, higher than the left end. It should be mentioned that no displacement restriction device exists between the girder segments and the piers, thus very large relative displacements occur to the elastomeric bearing pads, which allows the bridge pier to move together with the ground surface with insignificant damages occurring. Because the longitudinal permanent displacement of Side 2 is much larger than that of Side 1 as shown in Fig. 10, most of the differential displacement across the fault is accommodated by the relative displacement between Pier 2 and the middle and right girder segments (see Fig. 11 when $t=20 \mathrm{~s}$ ), which therefore resulted in the unseating of the right span only. It also should be mentioned that in the transverse direction, the response of the bridge is dominated by the dynamic component, and the reason is that the input ground motions in the transverse direction have relatively small permanent ground displacements.

As mentioned in Section 2.4, the broadband across-fault ground motions are dominated by the low-frequency components. For comparison, the corresponding low- 

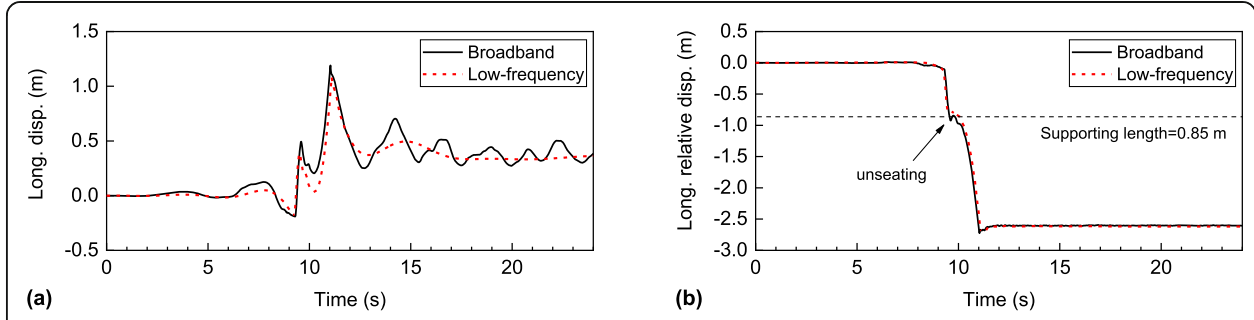

Fig. 12 a Longitudinal displacement time histories of Point $A$; $\mathbf{b}$ Longitudinal relative displacement time histories between Points $\mathrm{A}$ and $\mathrm{B}$

frequency across-fault ground motions (see Site 5 in Fig. 5) are also used to excite the bridge structure, and it is found that the collapse process of the bridge is almost identical to the results excited by the broadband across-fault ground motions as shown in Fig. 11. The collapse process is not presented to avoid repetition. Figure 12 compares the displacement time histories of the right span subjected to the broadband and lowfrequency across-fault ground motions. For a straightforward demonstration, the left end of the right span is denoted by Point $\mathrm{A}$, and the upper end of the right pier is denoted by Point $B$ as shown in Fig. 11. It can be seen from Fig. 12a that the displacement time history of Point A excited by the low-frequency ground motions shows close peak and residual displacements compared to that excited by the broadband ground motions. For the relative displacement between Points A and B as shown in Fig. 12b, very close results are obtained, implying the process of girder unseating due to the broadband and low-frequency across-fault ground motions are almost the same.

It should be noted that the bridge is assumed to cross the surface fault rupture in $90^{\circ}$, and the thrust fault generates very large differential displacements in both longitudinal and vertical directions with most of the static offsets generated on Side 2 (i.e. the hanging-wall side). This particular boundary condition results in the above collapse mode of the simply-supported bridge. In fact, similar scenarios were observed for the fault-crossing bridges in the 1999 Chi-Chi earthquake. For example, the E-Jian Bridge was a 24-span simply-supported bridge. During the earthquake, 12 spans in the northern half of the bridge collapsed (see Fig. 13), while the other 12 spans in the southern half of the bridge remained standing with minor damages. A field examination indicated that some of the piers in the northern portion moved towards the center of the river channel as rigid bodies,

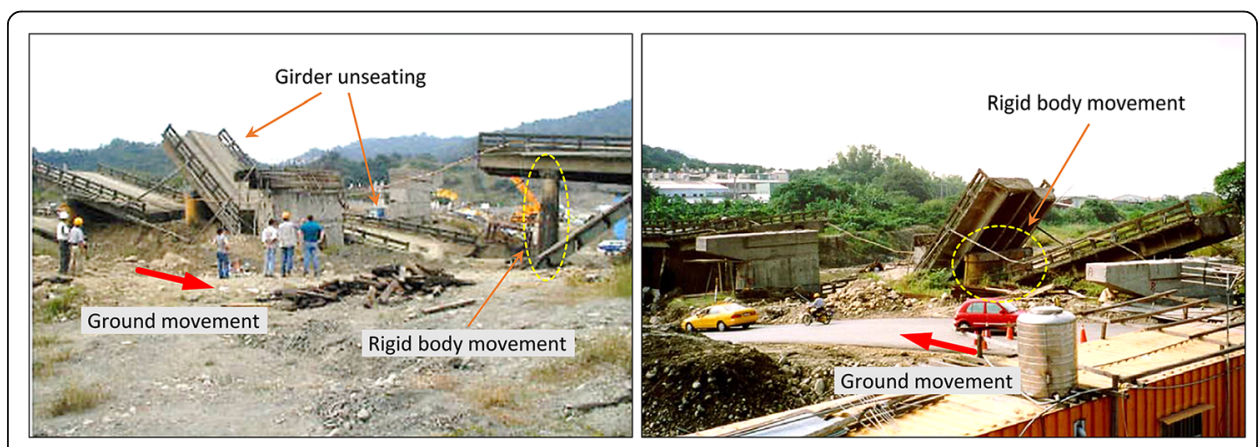

Fig. 13 The collapsed spans of the E-Jian Bridge due to surface faulting movement. Images are modified from Lee and Loh (2000) 
while the residual displacements in the southern piers were insignificant (Lee and Loh 2000). Thus, it is confirmed that the collapse was due to the gross movements of the northern substructures with relative displacements exceeding the supporting length of the bridge piers, instead of the excessive structural dynamic vibrations. It should be mentioned that the elastomeric bearing pads between the superstructure and the substructure are weak to resist large relative displacements. Thus, displacement restriction devices or isolation bearings may be introduced to reduce the relative displacements and possibly prevent unseating of the superstructure for simply-supported bridges crossing fault-rupture zones.

\section{Conclusions}

In the present study, the across-fault ground motions at the fault-crossing bridges in the 1999 Chi-Chi earthquake are simulated using the hybrid deterministic-stochastic method. A case study is then performed to investigate the seismic collapse mechanism of a typical simply-supported bridge under the across-fault ground motions. The main conclusions are summarized as follows:

1. The source-based hybrid deterministic-stochastic method can give reasonable predictions to the across-fault ground motions, which is useful for the seismic performance analyses of fault-crossing bridges.

2. The case study indicates that under the selected across-fault ground motions, the simply-supported bridge shows different damage modes on the two sides of the fault. In particular, unseating occurs to the bridge span on Side 2 (i.e. the hangingwall side), while on Side 1 (i.e. the footwall side), pounding damages occur to the ends of the girder segments.

3. Under the across-fault ground motions with pronounced fling-steps, the structural responses and collapse mechanism of the simply-supported bridge are dominated by the low-frequency ground motions. The large differential static offset across the fault is the main reason for the collapse of the simply-supported bridge.

It should be mentioned that under the across-fault ground motions with pronounced fling-steps, simply-supported bridges are very vulnerable. Displacement restriction devices and isolation bearings may be applied to mitigate the structural deformations induced by fault dislocation and avoid girder unseating, and this topic deserves further investigations.

Abbreviations

FE: Finite element; GMPE: Ground motion prediction equation; GPS: Global positioning system; PGA: Peak ground acceleration; PGV: Peak ground velocity; PGD: Peak ground displacement; DIF: Dynamic increase factor

Acknowledgments

The fault model from Finite-Source Rupture Model Database is acknowledged.

Authors' contributions

Yuanzheng Lin analyzed the data and was a major contributor in writing the manuscript. Zhouhong Zong provided ideas for this manuscript. Jin Lin managed the data analysis. Yale Li graphed the data. Yiyan Chen checked the analysis results. All authors have read and approved the final manuscript.

Funding

The National Natural Science Foundation of China (51678141). 


\section{Availability of data and materials}

The fault model and code for ground motion simulation during the study are available from the corresponding author by reasonable request. The FE model of the bridge is proprietary and may only be provided with restrictions.

\section{Competing interests}

The authors declare that they have no competing interests.

\section{Author details}

${ }^{1}$ Engineering Research Center of Safety and Protection of Explosion \& Impact of Ministry of Education (ERCSPEIME), Southeast University, Nanjing 211189, Jiangsu, China. ${ }^{2}$ School of Civil Engineering, Southeast University, Nanjing 211189, Jiangsu, China. ${ }^{3}$ Department of Building Engineering, Jiangsu Open University, Nanjing 210036, China. ${ }^{4}$ School of Civil Engineering, Fuzhou University, Fuzhou 350108, China.

\section{Received: 24 October 2020 Accepted: 16 December 2020}

\section{Published online: 03 March 2021}

\section{References}

Abrahamson NA, Silva WJ, Kamai R (2014) Summary of the ASK14 ground motion relation for active crustal regions. Earthquake Spectra 30(3):1025-1055. https://doi.org/10.1193/070913EQS198M

Aki K, Richards PG (1980) Quantitative seismology: theory and methods. W. H. Freeman and Company, San Francisco Anastasopoulos I, Gazetas G, Drosos V, Georgarakos T, Kourkoulis R (2008) Design of bridges against large tectonic deformation. Earthq Eng Eng Vib 7(4):345-368. https://doi.org/10.1007/s11803-008-1001-x

Beton CE-ld (1990) Concrete structures under impact and impulsive loading. CEB Bulletin 187. Federal Institute of Technology, Lausanne

Bi K, Hao H (2013) Numerical simulation of pounding damage to bridge structures under spatially varying ground motions. Eng Struct 46:62-76. https://doi.org/10.1016/j.engstruct.2012.07.012

Boore DM (1983) Stochastic simulation of high-frequency ground motions based on seismological models of the radiated spectra. Bull Seismol Soc Am 73(6A):1865-1894

Boore DM (2003) Simulation of ground motion using the stochastic method. Pure Appl Geophys 160:635-676

Boore DM, Joyner WB, Fumal TE (1997) Equations for estimating horizontal response spectra and peak acceleration from western north American earthquakes: a summary of recent work. Seismol Res Lett 68(1):128-153. https://doi.org/10.1785/ gssrl.68.1.128

Bouchon M (1979) Discrete wave number representation of elastic wave fields in three-space dimensions. J Geophys Res Solid Earth 84(B7):3609-3614

Bouchon M, Aki K (1977) Discrete wave-number representation of seismic-source wave fields. Bull Seismol Soc Am 67(2):259277

Burridge R, Knopoff L (1964) Body force equivalents for seismic dislocations. Bull Seismol Soc Am 54(6A):1875-1888

Chi W-C, Dreger D, Kaverina A (2001) Finite-source modeling of the 1999 Taiwan (Chi-Chi) earthquake derived from a dense strong-motion network. Bull Seismol Soc Am 91(5):1144-1157. https://doi.org/10.1785/0120000732

D'Amico S, Akinci A, Malagnini L (2012) Predictions of high-frequency ground-motion in Taiwan based on weak motion data. Geophys J Int 189(1):611-628. https://doi.org/10.1111/j.1365-246X.2012.05367.x

Ding Y, Mavroeidis GP, Theodoulidis NP (2019) Simulation of strong ground motion from the 1995 Mw 6.5 Kozani-Grevena, Greece, earthquake using a hybrid deterministic-stochastic approach. Soil Dyn Earthq Eng 117:357-373

Goel RK, Chopra AK (2009a) Linear analysis of ordinary bridges crossing fault-rupture zones. J Bridg Eng 14(3):203-215. https://doi.org/10.1061/(ASCE) 1084-0702(2009)14:3(203)

Goel RK, Chopra AK (2009b) Nonlinear analysis of ordinary bridges crossing fault-rupture zones. J Bridg Eng 14(3):216-224 https://doi.org/10.1061/(ASCE)1084-0702(2009)14:3(216)

Han Q, Du X, Liu J, Li Z, Li L, Zhao J (2009) Seismic damage of highway bridges during the 2008 Wenchuan earthquake. Earthq Eng Eng Vib 8(2):263-273. https://doi.org/10.1007/s11803-009-8162-0

Hui Y (2015) Study on ground motion input and seismic response of bridges crossing active fault. PhD thesis, Southeast University, Nanjing

Jankowski R (2012) Non-linear FEM analysis of pounding-involved response of buildings under non-uniform earthquake excitation. Eng Struct 37:99-105. https://doi.org/10.1016/j.engstruct.2011.12.035

Ji C, Helmberger DV, Wald DJ, Ma KF (2003) Slip history and dynamic implications of the 1999 Chi-Chi, Taiwan, earthquake. J Geophys Res Solid Earth 108(B9):2412. https://doi.org/10.1029/2002JB001764

Kamae K, Irikura K, Pitarka A (1998) A technique for simulating strong ground motion using hybrid Green's function. Bull Seismol Soc Am 88(2):357-367

Kawashima K, Takahashi Y, Ge H, Wu Z, Zhang J (2009) Reconnaissance report on damage of bridges in 2008 Wenchuan, China, earthquake. J Earthq Eng 13(7):965-996. https://doi.org/10.1080/13632460902859169

Lee GC, Loh C-H (2000) The Chi-Chi, Taiwan earthquake of September 21, 1999: reconnaissance report. The Multidisciplinary Center for Earthquake Engineering Research, State University of New York at Buffalo, Buffalo

Lekshmy P, Raghukanth S (2019) Stochastic earthquake source model for ground motion simulation. Earthq Eng Eng Vib 18(1):1-34

Lin Y, Chen Y, Zong Z, Lin J, Tang G, He X (2021) A new hybrid input strategy to reproduce across-fault ground motions on multi-shaking tables. J Test Eval 49(2):20190797. https://doi.org/10.1520/JTE20190797

Lin Y, Zong Z, Bi K, Hao H, Lin J, Chen Y (2020a) Experimental and numerical studies of the seismic behavior of a steelconcrete composite rigid-frame bridge subjected to the surface rupture at a thrust fault. Eng Struct 205:110105. https:// doi.org/10.1016/j.engstruct.2019.110105

Lin Y, Zong Z, Bi K, Hao H, Lin J, Chen Y (2020b) Numerical study of the seismic performance and damage mitigation of steel-concrete composite rigid-frame bridge subjected to across-fault ground motions. Bull Earthq Eng 18(15):6687-6714. https://doi.org/10.1007/s10518-020-00958-1 
Lin Y, Zong Z, Tian S, Lin J (2018) A new baseline correction method for near-fault strong-motion records based on the target final displacement. Soil Dyn Earthq Eng 114:27-37. https://doi.org/10.1016/j.soildyn.2018.06.036

Liu T, Atkinson GM, Hong H, Assatourians K (2012) Intraevent spatial correlation characteristics of stochastic finite-fault simulations. Bull Seismol Soc Am 102(4):1740-1747

LSTC (2016) LS-DYNA keyword user's manual R9.0. Livermore Software Technology Corporation, Livermore

Ma K-F, Mori J, Lee S-J, Yu S (2001) Spatial and temporal distribution of slip for the 1999 Chi-Chi, Taiwan, earthquake. Bull Seismol Soc Am 91(5):1069-1087. https://doi.org/10.1785/0120000728

Mai PM. Finite-Source Rupture Model Database (SRCMOD). 2015. http://equake-rc.info/SRCMOD/

Malvar $L$ (1998) Review of static and dynamic properties of steel reinforcing bars. ACl Mater J 95(5):609-616

Malvar LJ, Ross CA (1998) Review of strain rate effects for concrete in tension. ACl Mater J 95(6):735-739

Motazedian D, Atkinson GM (2005) Stochastic finite-fault modeling based on a dynamic corner frequency. Bull Seismol Soc Am 95(3):995-1010

NCREE (2002) 921 Chi-Chi earthquake on-line museum. National Center for Research on Earthquake Engineering http://www. ncree.org/921_bridge_project/

Olson AH, Orcutt JA, Frazier GA (1984) The discrete wavenumber/finite element method for synthetic seismograms. Geophys J Int 77(2):421-460. https://doi.org/10.1111/j.1365-246X.1984.tb01942.x

Pamuk A, Kalkan E, Ling H (2005) Structural and geotechnical impacts of surface rupture on highway structures during recent earthquakes in Turkey. Soil Dyn Earthq Eng 25(7-10):581-589. https://doi.org/10.1016/j.soildyn.2004.11.011

Papageorgiou AS (2003) The barrier model and strong ground motion. Pure Appl Geophys 160(3-4):603-634

Park S, Ghasemi H, Shen J, Somerville P, Yen W, Yashinsky M (2004) Simulation of the seismic performance of the Bolu Viaduct subjected to near-fault ground motions. Earthq Eng Struct Dyn 33(13):1249-1270. https://doi.org/10.1002/eqe.395

Roumelioti Z, Beresnev IA (2003) Stochastic finite-fault modeling of ground motions from the 1999 Chi-Chi, Taiwan, earthquake: application to rock and soil sites with implications for nonlinear site response. Bull Seismol Soc Am 93(4): 1691-1702. https://doi.org/10.1785/0120020218

Roussis PC, Constantinou MC, Erdik M, Durukal E, Dicleli M (2003) Assessment of performance of seismic isolation system of Bolu Viaduct. J Bridg Eng 8(4):182-190. https://doi.org/10.1061/(ASCE)1084-0702(2003)8:4(182)

Saiidi MS, Vosooghi A, Choi H, Somerville P (2013) Shake table studies and analysis of a two-span RC bridge model subjected to a fault rupture. J Bridg Eng 19(8):A4014003. https://doi.org/10.1061/(ASCE)BE.1943-5592.0000478

Shin T-C, Teng T-I (2001) An overview of the 1999 Chi-Chi, Taiwan, earthquake. Bull Seismol Soc Am 91(5):895-913. https://doi.org/10.1785/0120000738

Somerville PG (2002) Characterizing near fault ground motion for the design and evaluation of bridges. In: 3rd national seismic conference and workshop on bridges and highways, Portland, Oregon

Spudich P, Archuleta RJ (1987) Techniques for earthquake ground-motion calculation with applications to source parameterization of finite faults. In: Bolt BA (ed) Seismic strong motion synthetics. Academic, Orlando, pp 205-265

Sun X, Hartzell S, Rezaeian S (2015) Ground-motion simulation for the 23 August 2011, Mineral, Virginia, earthquake using physics-based and stochastic broadband methods. Bull Seismol Soc Am 105(5):2641-2661

Tang EK, Hao H (2010) Numerical simulation of a cable-stayed bridge response to blast loads, part I: model development and response calculations. Eng Struct 32(10):3180-3192. https://doi.org/10.1016/j.engstruct.2010.06.007

Ucak A, Mavroeidis GP, Tsopelas P (2014) Behavior of a seismically isolated bridge crossing a fault rupture zone. Soil Dyn Earthq Eng 57:164-178. https://doi.org/10.1016/j.soildyn.2013.10.012

Wang G-Q, Zhou X-Y, Zhang P-Z, Igel H (2002) Characteristics of amplitude and duration for near fault strong ground motion from the 1999 Chi-Chi, Taiwan earthquake. Soil Dyn Earthq Eng 22(1):73-96. https://doi.org/10.1016/S0267$7261(01) 00047-1$

Wu C, Takeo M, Ide S (2001) Source process of the Chi-Chi earthquake: a joint inversion of strong motion data and global positioning system data with a multifault model. Bull Seismol Soc Am 91 (5):1128-1143. https://doi.org/10.1785/ 0120000713

Yang S, Mavroeidis GP (2018) Bridges crossing fault rupture zones: a review. Soil Dyn Earthq Eng 113:545-571. https://doi.org/10.1016/j.soildyn.2018.03.027

Yang S, Mavroeidis GP, Ucak A (2020) Analysis of bridge structures crossing strike-slip fault rupture zones: a simple method for generating across-fault seismic ground motions. Earthq Eng Struct Dyn 49(13):1281-1307. https://doi.org/10.1002/eqe.3290

Zhang F, Li S, Wang J, Zhang J (2020) Effects of fault rupture on seismic responses of fault-crossing simply-supported highway bridges. Eng Struct 206:110104. https://doi.org/10.1016/j.engstruct.2019.110104

\section{Publisher's Note}

Springer Nature remains neutral with regard to jurisdictional claims in published maps and institutional affiliations. 